\title{
A Farm Sanctuary Tour's Effects On Intentions And Diet Change
}

\section{Background}

Farm sanctuaries exist to save animals from harmful environments and to give them their "forever home," where they are kept safe for the remainder of their lives. Farm sanctuaries were created specifically in response to the violence that farmed animals experience in factory farms (Donaldson \& Kymlicka, 2015). There are hundreds of farm sanctuaries in the United States (Compassionate Farming Education Initiative, n.d.). Although sanctuaries have a primary function of rescuing farmed animals, many farm sanctuaries advocate for animal rights and veganism, engage in public outreach and fundraising, and are open to the public for visitations in order to help shift the perception of farmed animals.

Farm Sanctuary--where this research was conducted--was founded in 1986 and is one of the oldest farm sanctuaries in the United States. Their mission is to reduce cruelty against animals, instill compassion, and promote the benefits of a plant-based lifestyle to create incremental change in the fight for animal rights. In addition to rescuing animals and raising awareness about the impact of the agricultural industry, Farm Sanctuary advocates for the local and national reform of institutional policies regarding factory farming.

Farm Sanctuary has two locations: one in New York and one in California. They collectively have 10,000 visitors per year and house over 900 animals, including pigs, cows, chickens, turkeys, and other farmed animals.

This research project was contracted by Farm Sanctuary as a program evaluation of their on-site tours. With the generous permission of Farm Sanctuary, we are sharing the results with the broader community in order to help increase the understanding of the role that a well-run sanctuary can play in vegan advocacy. 


\section{Key Findings}

1. The tour led to significant changes in people's intentions to reduce their consumption of animal products, and people's reported diets changed in the two months after the tour. People were more likely to report wanting to reduce meat and animal product consumption after the tour than before it. People reported reductions in their consumption of all of the measured types of animal products in the two months after leaving the sanctuary.

2. The tour encouraged meaningful changes in people's understanding of how dietary choices impact animal suffering. Attendees' beliefs in the link between dietary choices and animal suffering were stronger after the tour than before, and these beliefs remained over time.

3. Tour attendees experienced shock and disgust after learning about the way animals are treated on factory farms. Many also contrasted this with a sense of peace and rejuvenation they felt at the sanctuary.

4. Direct experiences with the animals were the most memorable parts of the tour. This aspect of the tour also elicited the most excitement and enthusiasm. Some participants contrasted it favorably with being exposed to other forms of advocacy.

5. Messages about the cruelty that farmed animals are subjected to is crucial, and was successful when paired with a soft approach to persuasion. Tour attendees learned the truth about factory farming from guides who presented information about how diet change can help but were not pushy or judgmental. Several attendees commented that they appreciated that the messages conveyed the necessary information, but felt balanced. They did not put so much pressure on individuals that they would become defensive.

\section{Research Team}

This project was led by Faunalytics' Research Scientist, Tom Beggs (MA), and supervised/co-authored by Faunalytics' Research Director, Dr. Jo Anderson. The interviews were conducted by Dr. Anderson. 


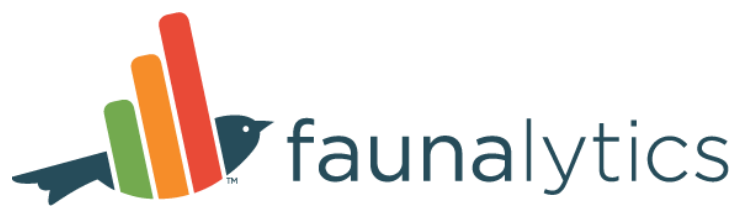

\section{Acknowledgments}

We are very grateful to Farm Sanctuary for the opportunity to conduct this evaluation and for agreeing to share the results. Thanks also to all of the participants who provided us with their perspective, and to Blake Miller for his assistance with this report. 


\section{Survey Method \& Results}

\section{Method}

To evaluate the impact of the tours, participants were invited to complete two surveys: one on-site and one three months later. On-site paper and pencil surveys were completed between July and September 2019 at both the Watkins Glen and Acton locations.

A total of 1,230 people participated. This represents a substantial proportion of Farm Sanctuary's visitors per year. It was the first visit to Farm Sanctuary for $80 \%$ of respondents. Participants completed the survey either before or after the tour (determined randomly). This was done to determine whether attitudes or intentions were affected by the tour itself. By design, most participants (82\%) completed the survey after they took the tour.

The follow-up survey three months later was administered online through the Qualtrics survey platform. Participants were given an entry into a $\$ 100$ drawing.

\section{Sample}

The sample on the farm was $69 \%$ female and $29 \%$ male. The remaining $2 \%$ were write-ins for families or non-binary people. $11 \%$ of the sample identified as a person of color, $11 \%$ identified as LGBTQ+, and $3 \%$ identified as having a disability. Only $40 \%$ of people of color provided more detail, but of those, $59 \%$ identified as Latino/Latina/Latinx, $23 \%$ as Asian, $11 \%$ as Black, and $8 \%$ another way.

$23 \%$ of respondents were under 25 years of age, $26 \%$ were between 25 and $34,20 \%$ were between 35 and 44 , and $30 \%$ were over the age of 45 . The median attendee was in the 35-44 age group.

There were no significant differences in how people described their current diets when they were asked before or after the tour. This is a good sign that the people in the two groups were similar to begin with (which is necessary in order to meaningfully compare their responses), and that they were not just saying what they thought we wanted to hear after the tour. As a note, the pre-tour group was younger (median age of 25-34) than the post-tour group (median 35-44, $p=$ .04). The groups had a similar make-up in terms of gender, and the proportions who identified as a person of color, as a person with a disability, or as LGBTQ+. The difference in age would not likely have much impact on the results. 
The follow-up surveys were completed between two and three months after each participant's original sanctuary visit. There were 559 valid email addresses provided, which resulted in 215 usable survey responses. There was a danger of non-response bias in the follow-up survey answers: They come from a group of people who were already consuming fewer animal products and were more amenable to change than those who didn't respond. The results must therefore be interpreted as relating to a particular subset of tour attendees. See the Limitations section for more detail.

\section{Results}

In the sections below, we provide a subset of the themes identified in the full evaluation that we feel will be useful to advocates and of interest in understanding the role of sanctuaries in advocacy. Note that because this work began as a contract project, it was not pre-registered and we do not have participants' consent to host their de-individuated data on the Open Science Framework.

\section{Diet}

Figure 1 shows participants' diets at the time they visited the sanctuary. As would be expected, vegetarians and vegans are over-represented compared to the population at large. Figure 2 shows the frequency of participants' reported consumption of different animal products. 


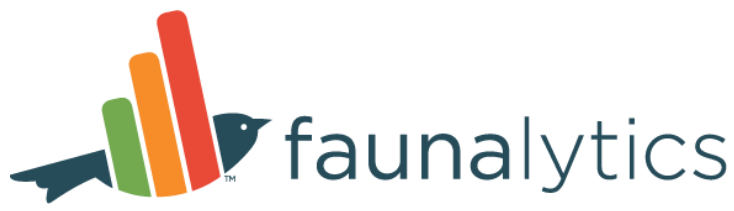

Figure 1: Reported Diets Of Participants

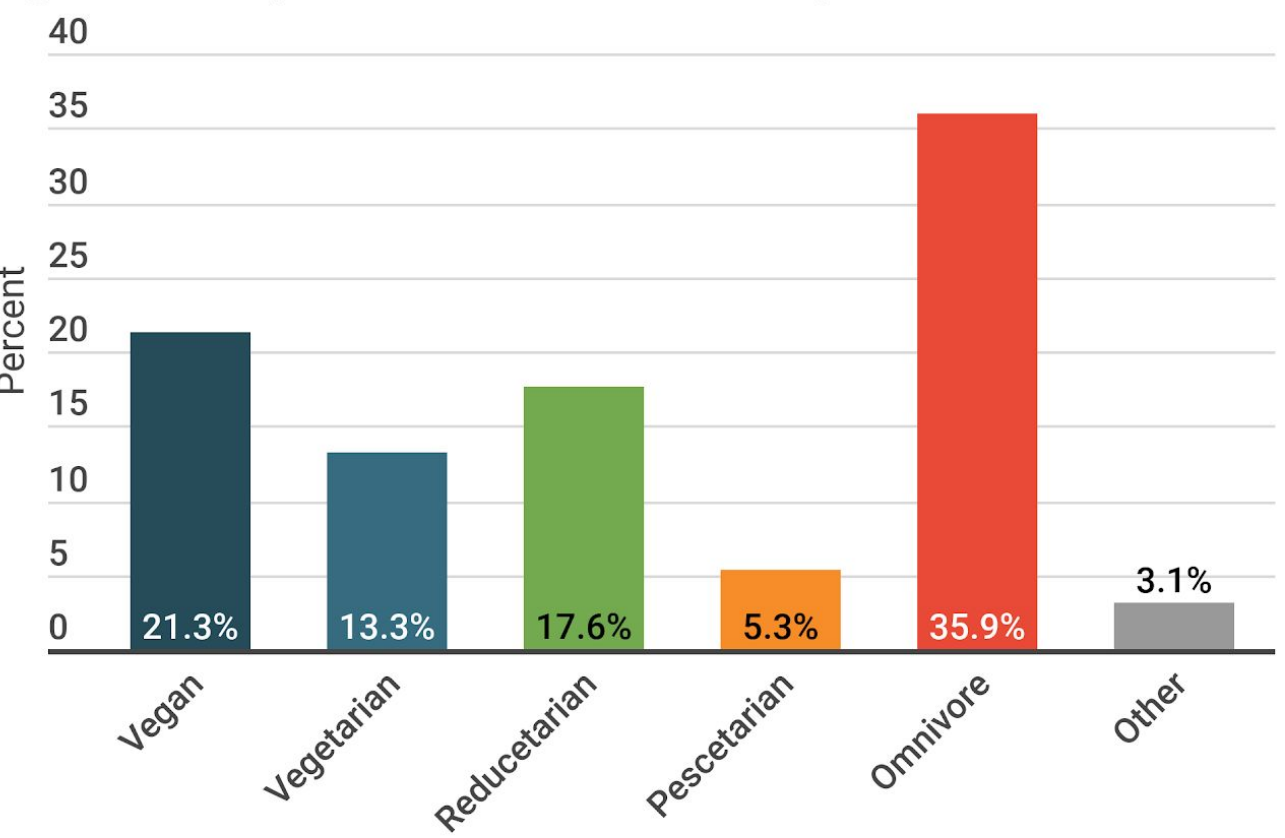

Note: The reducetarian category includes flexitarian and semi-vegetarian 


\section{A. faunalytics}

Figure 2: Frequency Of Animal Product Consumption

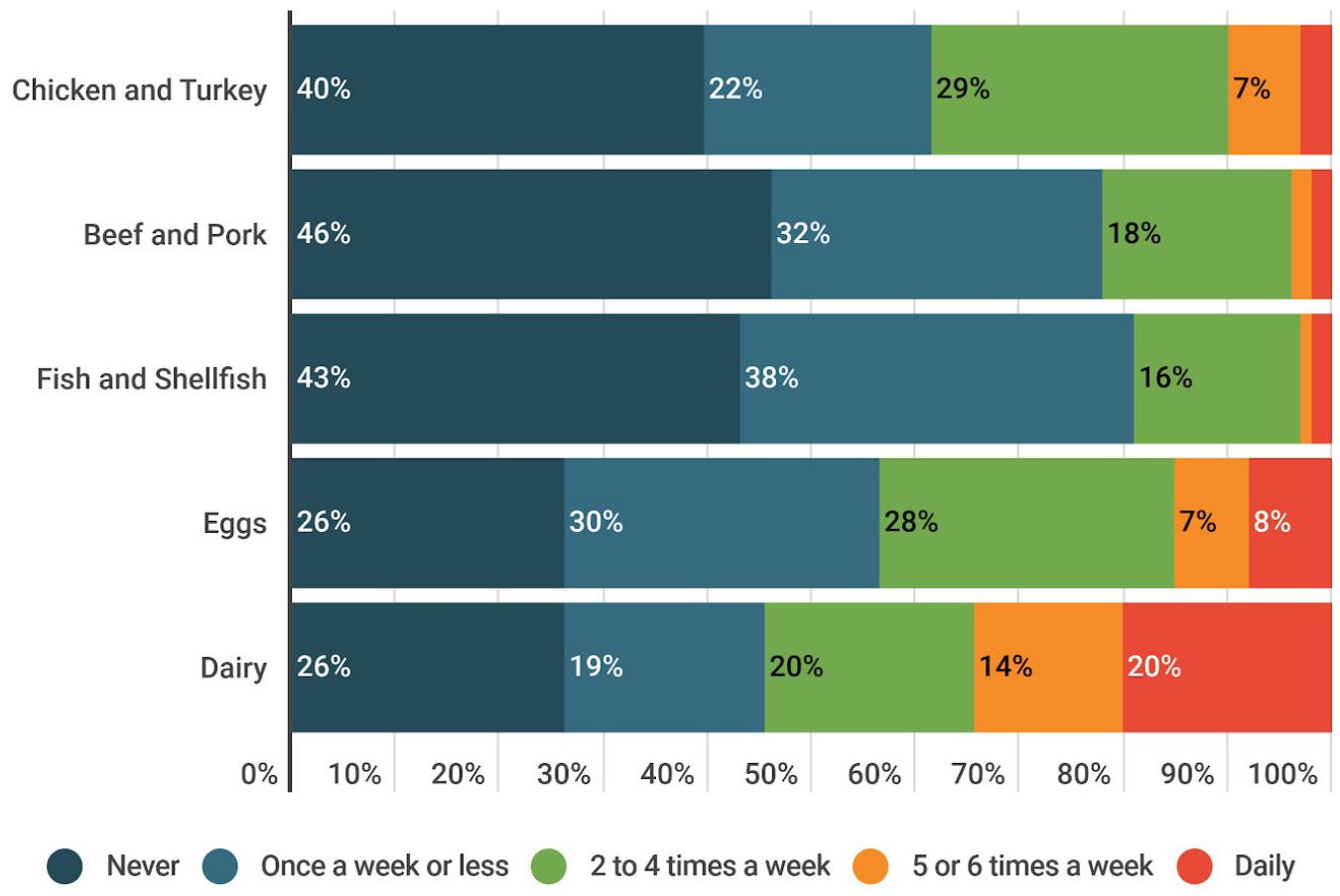

Participants who did the survey before the tour selected one or more reasons for attending, which are presented in Table 1 below. The most popular reason was to interact with the animals. The importance of interaction was a common theme in the qualitative findings as well, as described in the Interview Method \& Results section. About half of the participants also reported coming to have fun and to learn about farm animals. 


\section{Table 1: Reasons For Attending The Tour}

\begin{tabular}{|l|c|}
\hline Reason & Percent Endorsement \\
\hline To see and interact with farm animals & $68 \%$ \\
\hline To have fun & $51 \%$ \\
\hline To learn more about farm animals & $48 \%$ \\
\hline Attending with someone else who wanted to come & $25 \%$ \\
\hline For something to do in the local area & $21 \%$ \\
\hline To learn more about factory farming & $19 \%$ \\
\hline To have an emotional experience & $18 \%$ \\
\hline To motivate yourself to become or stay vegan & $16 \%$ \\
\hline To motivate yourself to become or stay vegetarian & $11 \%$ \\
\hline To choose or visit an "adopted" animal & $7 \%$ \\
\hline
\end{tabular}

Note: Participants could endorse multiple reasons

\section{Beliefs}

There was no difference between the pre- and post-tour groups on whether attendees thought farmed animals had unique personalities or could feel pain and pleasure like dogs and cats. However, people already endorsed both of these items very highly in the pre-tour survey (means of 3.78 and 3.83 out of 4 , respectively).

Participants in the post-tour group were significantly more likely to make a connection between diet and animal suffering (mean 3.60) than people in the pre-tour group (mean 3.33; $p<.001$ ). In fact, strong agreement increased by over a third, while every other response option was picked less frequently by the post-tour group (see Figure 3). This shows a meaningful shift in attitudes. 


\section{0 faunalytics}

\section{Figure 3: Diet And Suffering}

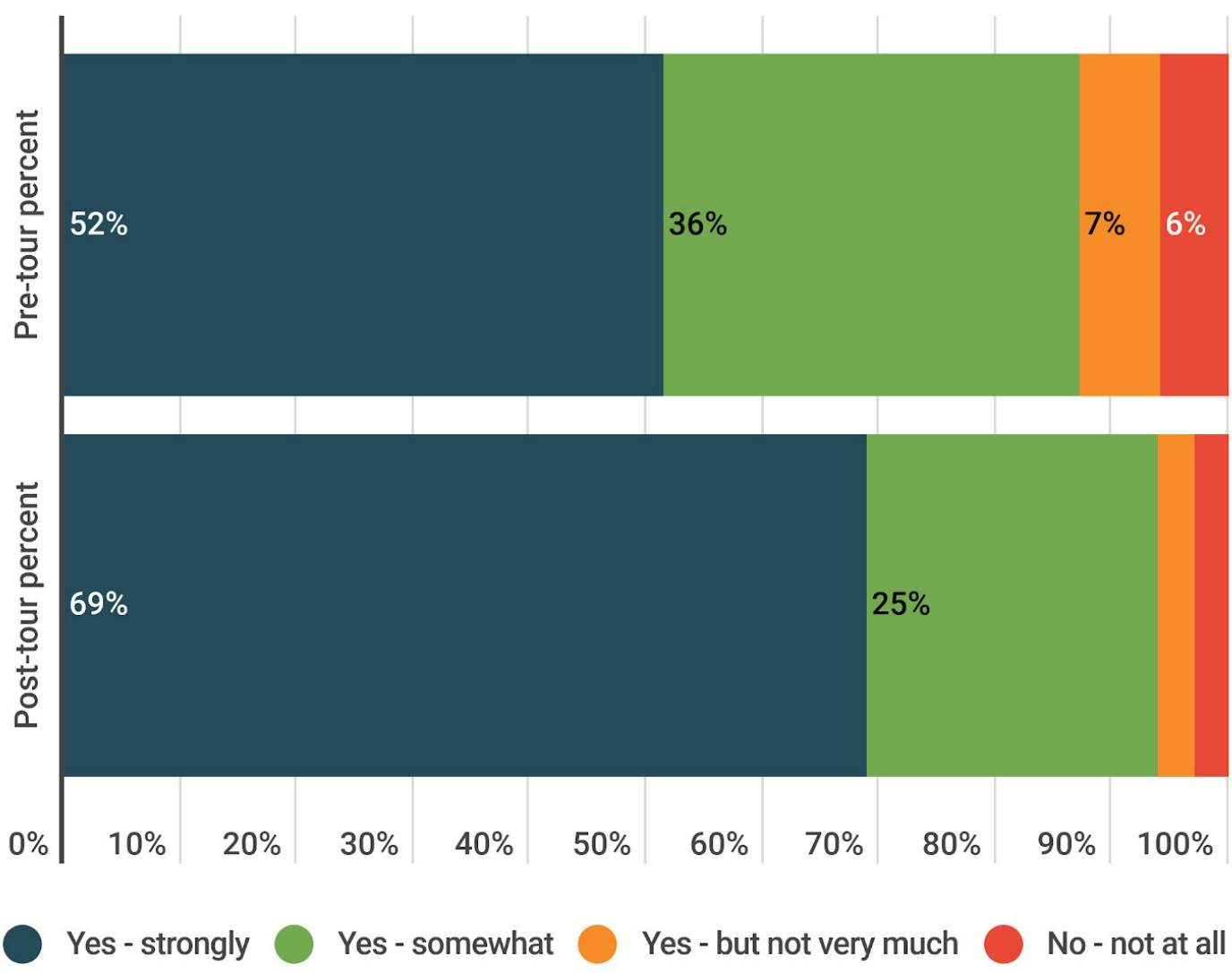

Note: Responses to the question "Do you believe that people directly contribute to the suffering of farm animals when they choose animal-based foods like meat and dairy products?"

\section{Activities And Diet Change}

People were also asked about things they were likely to do in the next 2-3 months. The rates of endorsement shown in Table 2 below did not differ between pre-tour and post-tour respondents with one exception: $76 \%$ of non-vegans said they would try making vegetarian or vegan meals after the tour compared to $66 \%$ of those who responded before the tour $(p=.007)$. 


\section{Table 2: Which Of The Following Are You Likely To Do} In The Next 2-3 Months?

\begin{tabular}{|l|c|}
\hline & $\begin{array}{c}\text { Percent } \\
\text { Endorsement }\end{array}$ \\
\hline Try making vegetarian/vegan meals & $78 \%$ \\
\hline Talk with friends about vegetarianism/veganism & $48 \%$ \\
\hline Visit the Farm Sanctuary website & $39 \%$ \\
\hline Buy a vegetarian/vegan cookbook & $27 \%$ \\
\hline Attend a vegetarian/vegan-themed event & $27 \%$ \\
\hline $\begin{array}{l}\text { View online videos about vegetarianism/veganism or farm } \\
\text { animals }\end{array}$ & $27 \%$ \\
\hline Visit a Farm Sanctuary location & $21 \%$ \\
\hline $\begin{array}{l}\text { Participate in an online forum/community about } \\
\text { vegetarian/vegan eating }\end{array}$ & $18 \%$ \\
\hline Note: Participants could endorse multiple reasons & \\
\hline
\end{tabular}

As can be seen in Figure 4,70\% of non-vegans said that they planned to make a change in their diet after the tour compared to just $53 \%$ before $(p<.001)$. Reducing animal product consumption was the most common intended change. The increase in the number of people intending to go vegan was notable (from $9 \%$ pre to $15 \%$ post), though it did not reach statistical significance $(p>.05)$. 


\section{Paunalytics}

\section{Figure 4: Planned Dietary Changes}

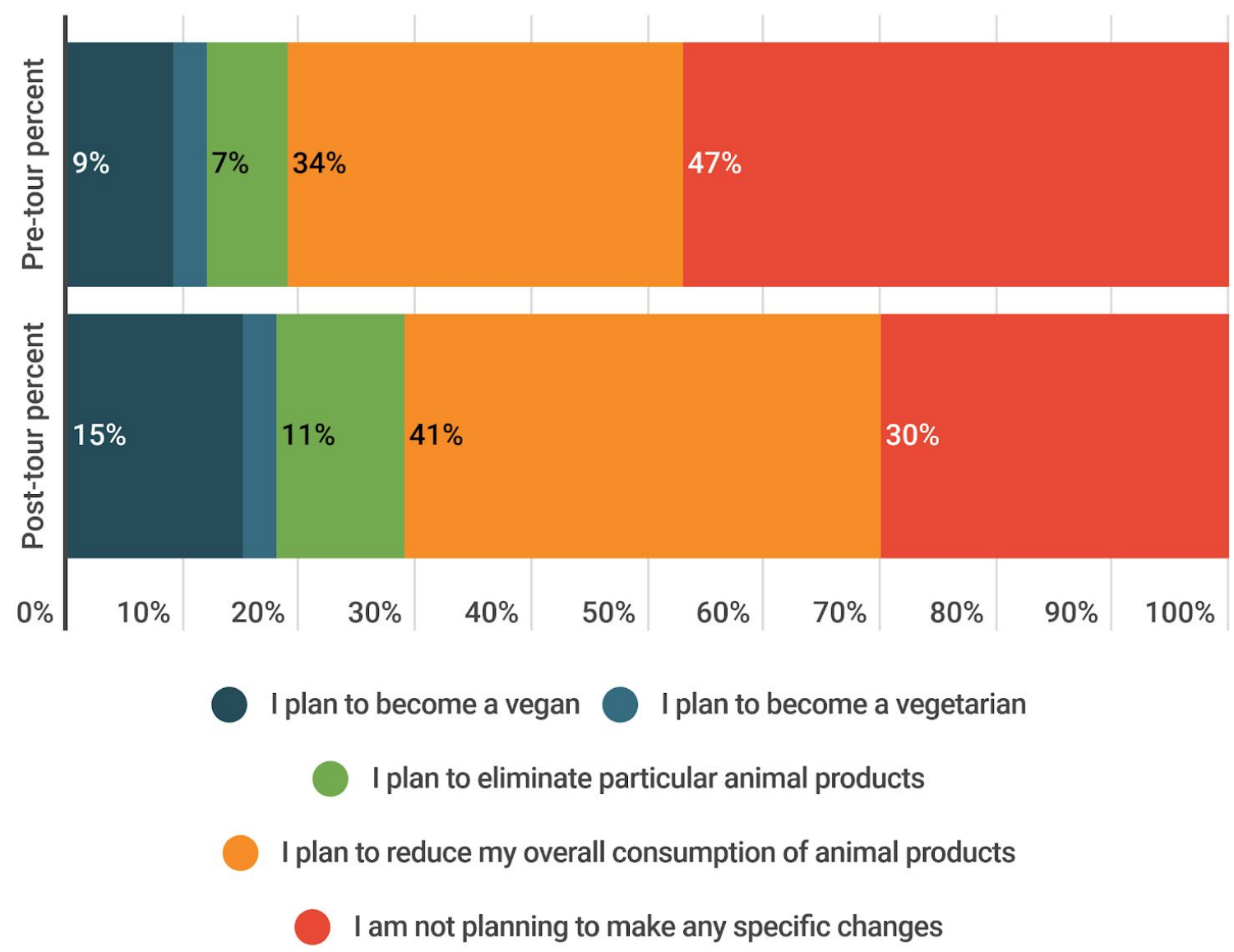

The survey also asked about participants' intentions with respect to eating specific categories of animal products, as shown in Figure 5 below. Compared to pre-tour respondents, people who responded post-tour were significantly more likely to say they planned to eat less of each animal product (see numbers in Figure 5; all ps <.05). Those who already abstain were excluded from analyses. 


\section{-1) faunalytics}

Figure 5: Intended Changes In Animal Product Consumption

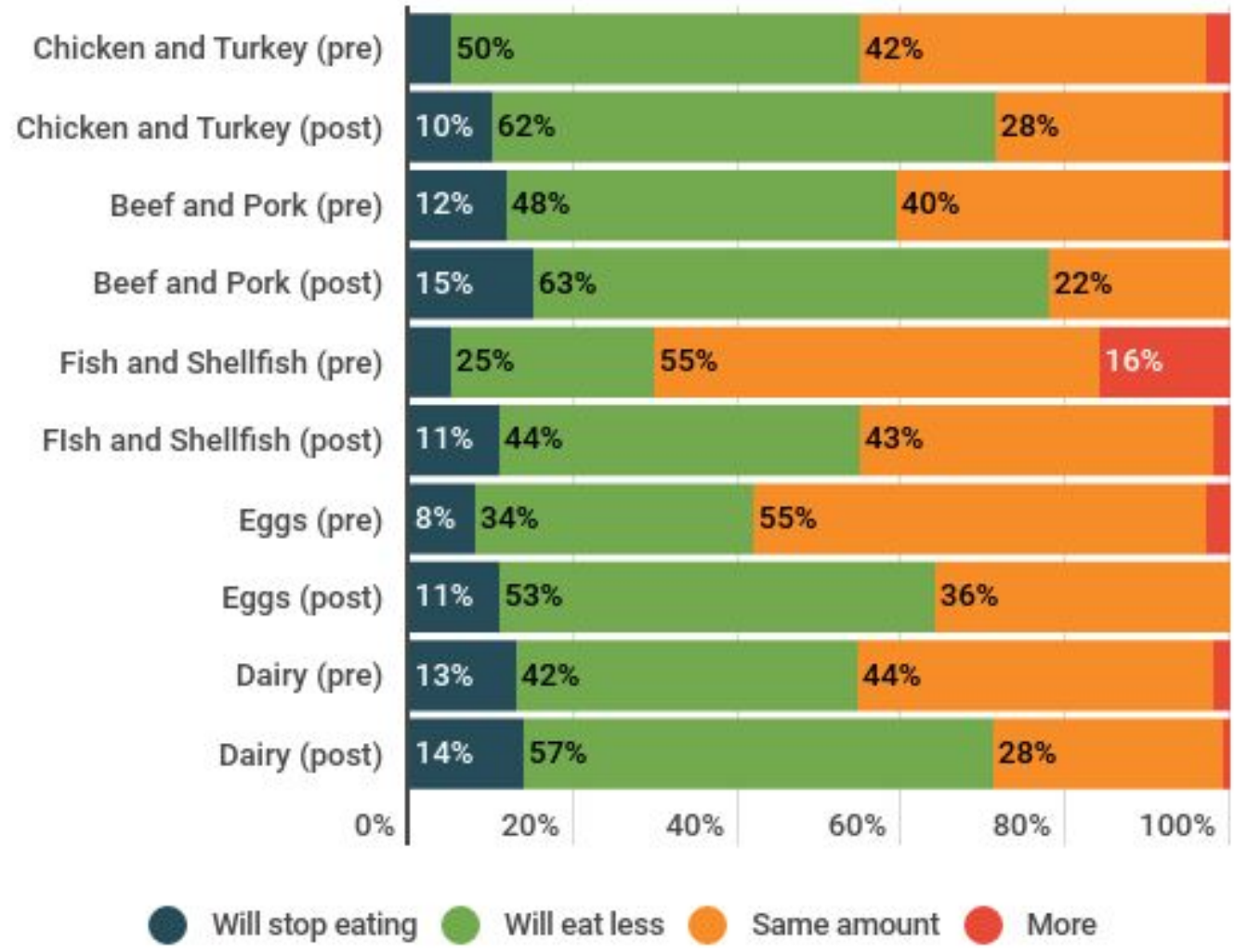

Most respondents were confident in their ability to make dietary changes--only $4 \%$ said they were not at all or not very confident, while $32 \%$ were somewhat confident, $31 \%$ very confident, and $33 \%$ extremely confident.

In terms of the motivations for these changes, non-vegan/vegetarian participants were asked what part of the tour made them most interested in moving towards those diets. $53 \%$ of participants chose "learning about farm animal cruelty," $23 \%$ chose "observing and learning about the animals," $6 \%$ chose "learning about humane labels," and $2 \%$ chose "the tour video." An additional $11 \%$ chose "none of the above," and $4 \%$ chose "other."

Overall, participants were very satisfied with the tour: $68 \%$ said that they were extremely happy, and $24 \%$ said that they were very happy. Less than $4 \%$ chose the neutral "somewhat happy" option, four people (less than half a percent) chose "not very happy," and no one chose "not at all happy." 


\section{-1)}

\section{Key Changes Over Time}

The current section covers the major changes between when participants were on the tour and the follow-up $\sim 3$ months later.

\section{Changes In Diet}

A non-response bias analysis revealed that the follow-up sample was made up of people who ate fewer animal products to begin with than the general tour sample. Even so, this group still significantly reduced the amount of animal products they consumed from when they visited Farm Sanctuary to the follow-up, as shown in Figure 6 (all $p s<.05$ ). 


\section{Figure 6: Frequency Of Animal Product Consumption, Farm To Follow-Up Comparison}

\begin{tabular}{|c|c|c|c|c|c|c|c|}
\hline Chicken and Turkey (on-site) & $54 \%$ & & & $21 \%$ & 20 & $\%$ & \\
\hline Chicken and Turkey (follow-up) & $64 \%$ & & & & $17 \%$ & $15^{\circ}$ & \\
\hline Beef and Pork (on-site) & $65 \%$ & & & & $22 \%$ & & $12 \%$ \\
\hline Beef and Pork (follow-up) & $70 \%$ & & & & $22 \%$ & & $9 \%$ \\
\hline Fish and Shellfish (on-site) & $59 \%$ & & & & $6 \%$ & & $14 \%$ \\
\hline Fish/Shellfish (follow-up) & $64 \%$ & & & & $25 \%$ & & $9 \%$ \\
\hline Eggs (on-site) & $35 \%$ & 27 & & & $26 \%$ & & $6 \% 6 \%$ \\
\hline Eggs (follow-up) & $43 \%$ & & $32 \%$ & & $20^{\circ}$ & & \\
\hline Dairy (on-site) & $39 \%$ & & $17 \%$ & $17 \%$ & $14 \%$ & & $14 \%$ \\
\hline Dairy (follow-up) & $43 \%$ & & $20 \%$ & & $18 \%$ & $9 \%$ & $11 \%$ \\
\hline $0 \%$ & $20 \%$ & $40 \%$ & & $60 \%$ & $80 \%$ & & $100 \%$ \\
\hline
\end{tabular}

Table 3 shows the self-reported diets of 205 people who completed both the on-site and follow-up diet questions. Their original diet is listed on the left. The data columns show whether their diet changed negatively (further from veganism), not at all, or positively (closer to veganism). Shifts in the direction of omnivore $\rightarrow$ reducetarian $\rightarrow$ pescetarian $\rightarrow$ vegetarian $\rightarrow$ vegan were considered positive, and the opposite negative.

The results show a shift toward veganism among omnivores in particular -- one third of initial omnivores reported a positive change. 
Table 3: Change In Described Diet From On-Site Survey To Follow-Up

Diet at follow-up

\begin{tabular}{|l|c|c|c|c|}
\hline Diet On-Site & Further from vegan & No change & Closer to vegan & Positive Change \\
\hline Omnivore & N/A & 26 & 13 & +13 \\
\hline Reducetarian & 4 & 28 & 9 & +5 \\
\hline Pescetarian & 0 & 6 & 1 & +1 \\
\hline Vegetarian & 2 & 31 & 5 & +3 \\
\hline Vegan & 0 & 70 & N/A & N/A
\end{tabular}

\section{Continued Diet Intentions}

On site, participants were asked whether they intended to eat more or less of each animal product. Comparing these initial intentions to intentions at follow-up provides a sense of whether motivation had faded. Among those who still consumed at least some of these products, the proportion of people who intended to reduce or eliminate them remained high: $90 \%$ for beef and pork, $73 \%$ for chicken and turkey, $73 \%$ for dairy, $66 \%$ for eggs, and $46 \%$ for fish and shellfish. This set of findings suggests that even though diets had already shifted significantly 3 months later, they still intended to shift more in the future.

\section{Beliefs}

People's beliefs about animals did not change significantly over the follow-up period. That is, on average, there was no change in their beliefs about animals having individual personalities or feeling pain, nor about whether choosing to buy animal products contributes to animal suffering.

As mentioned previously, beliefs about animals having individual personalities and feeling pain were high regardless of whether people were asked before or after the tour, suggesting that the type of people who visited the tour already tend to believe these things. The same beliefs were still present at follow-up-at all time points, more than $80 \%$ of participants strongly agreed that animals have individual personalities, and more than $86 \%$ that animals are capable of feeling pain the way a companion animal does.

However, the belief that the consumption of animal products leads to suffering was significantly higher in the post-tour group than the pre-tour group, which suggests that the tour increased it. This increase also seems to have been maintained over the follow-up period (mean 3.78 on-site vs. 3.70 at follow-up, $p>.05)$. 


\section{Actions To Encourage Vegetarianism And Veganism}

Follow-up participants indicated that they had engaged in a wide range of advocacy activities after leaving the sanctuary, from having personal conversations about vegetarianism or veganism, to sharing information and resources, to bringing other people to animal-related events. These activities are described in Table 4 below. As would be expected, non-vegans had slightly lower endorsement rates.

\begin{tabular}{l|l|l|}
\hline Table 4: Types Of Engagement Since Being On The Tour \\
$\begin{array}{l}\text { Have you done any of the following to encourage others to } \\
\text { think about farm animals, vegetarianism, or veganism in the } \\
\text { past } 2 \text { months? }\end{array}$ & $\begin{array}{c}\text { Percent } \\
\text { endorsement } \\
\text { (full sample) }\end{array}$ & $\begin{array}{c}\text { Percent } \\
\text { endorsement } \\
\text { (non-vegans } \\
\text { only) }\end{array}$ \\
\hline $\begin{array}{l}\text { Had personal conversations (including email/online) about } \\
\text { vegetarianism/veganism }\end{array}$ & $73 \%$ \\
\hline $\begin{array}{l}\text { Had personal conversations (including email/online) about farm } \\
\text { animals }\end{array}$ & $64 \%$ \\
\hline $\begin{array}{l}\text { Shared resources about farm animals or } \\
\text { vegetarianism/veganism with family or friends }\end{array}$ & $57 \%$ \\
\hline $\begin{array}{l}\text { Shared information about farm animals or } \\
\text { vegetarianism/veganism on social networks }\end{array}$ & $46 \%$ \\
\hline $\begin{array}{l}\text { Brought someone to visit a farm animal sanctuary } \\
\text { Brought someone to attend an event related to farm animals or } \\
\text { vegetarianism/veganism }\end{array}$ & $42 \%$ & $35 \%$ \\
\hline
\end{tabular}

Participants also had strong follow-through on actions since being on the tour. Most notably, $85 \%$ said that they had tried to make a vegetarian or vegan meal and $82 \%$ said that they had talked to friends about vegetarianism/veganism. In addition, $35 \%$ said they had been to a vegan-themed event, and $33 \%$ had bought a vegetarian/vegan cookbook. Online engagement was also high, with $46 \%$ saying that they had viewed online videos about vegetarianism/veganism or farm animals, $36 \%$ saying they had visited the Farm Sanctuary website, and $25 \%$ saying that they had participated in an online forum. $46 \%$ of respondents also said that they had visited a Farm Sanctuary location in the past 2 months, but we think this was probably due to memory error for many: Although it had been over two months at the time of the follow-up survey, some may have been thinking of the visit when they completed the on-site survey. 


\section{Interview Method \& Results}

In order to gather richer information about the subjective experiences visitors have on-site, Faunalytics' Research Director Jo Anderson conducted structured interviews in person with people who had just completed a tour at Farm Sanctuary over a period of three days in July 2019.

\section{Participants}

Participants completed the interviews either alone or with one other person. To reduce the likelihood of bias from more motivated people participating, we offered $\$ 10$ per person for the half-hour interview.

Twenty-two people completed interviews. There were 13 people who identified as female and 9 who identified as male. The average age was 44, with a range between 19 and 69 years of age. There were six vegans, two vegetarians, one pescetarian, four omnivores, and nine reducetarians in the sample.

Qualitative interviews provide rich data and context for understanding people's experiences on the tour. However, the small sample size should be kept in mind when considering generalizations. The main themes to arise from the interviews are described below, with illustrative quotations included to provide additional context.

\section{Putting Farmed Animal Abuse Up Front}

At Farm Sanctuary, the tour begins with a video that includes some footage of farmed animal abuse; the tour guides also provide information on things like factory farms. Not surprisingly, reactions were somewhat mixed. Most people understood the importance of the information being presented in the film.

That said, a small number of people also reported that the video was hard to watch-these people were generally already vegetarian or vegan, and reported having a strong emotional response to it. However, only one of the twenty-two interviewees seemed to endorse removing the difficult-to-watch sections. There was additional information about animal cruelty presented through the course of the tour.

"I think they were fair. I don't think it was over-exaggerating to push an agenda. I think that they could even do more with the video to show more and - I don't think you want to shock people, but make them more aware [....] I'm not here every day, so it's hard to 
understand the overall tone and how people take in these things that are not already exposed to it. I think some more exposure to that kind of thing would be great."

"I thought it was effective [...]. There's clearly an agenda, which is the care and the compassion and trying to promote more plant-based diets, but it doesn't feel - I don't feel like l'm at church."

People also seemed to recognize the value of more graphic language and images in bringing about diet change.

"That's all it takes for me to not ever want to drink milk again. I'm easy. It just grosses me out. Tell me the horrific things, and I'm like, okay, I'm up."

"Sad. Just knowing how they're treated...definitely makes me want to not eat dairy or meat anymore. We've been really trying to."

"I'm disgusted at how the animals are killed and how they're kept. I don't want to eat any more."

Overall, then, it appears that it is possible to present unpleasant truths to sanctuary visitors without alienating them--at least if the organization walks the line successfully and conveys important information without being too graphic. It is important to note that tour guides also warn people about the video footage and give them the option to look away should they feel the need.

\section{Individual Interactions With The Animals}

Farm Sanctuary tours allow participants to have direct contact and meaningful interaction with the animals. Participant responses suggested that the one-on-one contact with the animals is the most impactful element of the tour. As described above, the survey showed that even before the tour, guests very strongly endorsed the idea that farmed animals (in general) have unique personalities. Despite this already-high level of agreement with the general question, interviewees after the tour still often talked about what an impression a particular animal had made on them. Sometimes it was a turkey asking for a massage, sometimes it was an ornery chicken giving someone a comedic peck on the back as they interacted with another bird, and sometimes it was a sheep nudging a person to demand more affection just like a dog would--but whatever the specifics, it was very clear that the face-to-face interactions with the animals had made a lasting impression on a large number of participants.

Importantly, a number of omnivores seemed to really make the connection in a way that could influence their diets going forward. People talked about their surprise at the personality, 
curiosity, and intelligence of animals like turkeys that are often depicted as being somewhat dull. Other remarks pointed to the mental divide between the experience of grocery shopping and the lives and personalities of the sentient animals they just met, and seemed to be genuinely pensive and reflective on that fact.

"I was just engulfed by sheep. It was great. They were just all coming on all sides. [laughter] It's amazing."

"It's one thing to watch a documentary and then the credits roll and then you go on to the next thing in your day. It's different when you hear the facts that are being told and then you get to meet the animal right there that went through it and you're like, 'Wow!'”

"I'm glad I got to interact with them so much. I wasn't anticipating being able to because you know that they're rescued animals [....] So as soon as they told us we could pet the cows, I was just ecstatic and just went from there--I got to love on all of them. [laughter]"

Another reasonably common theme was that the experience of meeting the animals reduced the psychological distance between the items in a grocery store and the animals used to produce them.

"Seeing them [...] in a sanctuary where they're protected, it kind of gives you a whole sort of emotional and visceral feeling of what these creatures are, as opposed to just something in the frozen food section at a grocery store."

\section{Happy Animals}

Another very common theme among participants was how happy the animals were. People were pleasantly surprised that they were so sociable and looking to interact rather than trying to get away from people as you often see in factory farm footage. People also reflected on the fact that it seemed like the animals had relatively simple needs in order to be peaceful and happy, and appreciated the idea that we are guests in the animals' homes while on tour, and that we should act accordingly.

"Giving them space and letting them be with each other is enough to bring wholeness to a life. [...] the animals just say, 'Can I have a little bit of room to move around? Can I just eat some grass? And I'm good with that and hang[ing] out with some friends. Then I'm fine.' That is so simple." 


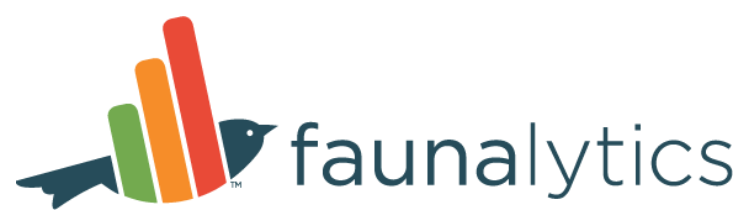

"One of the things I love about the farm is that they always are putting the animals first. They never put the people here on the tour first. They just say, 'you have to work around what's going on here."'

\section{Dietary Change - A Positive, Incremental Approach}

Dietary change is one of the most important outcomes that can arise from a tour. Another consistent theme was the fact that the tour encouraged this change in a gentle, considerate, and effective way. It encouraged people who were on the path to veganism to make additional changes and got omnivores thinking about taking the first steps. People also seemed realistic in their goals, talking about possible barriers and the fact that change may take time.

A number of people talked about the challenges of trying to eliminate animal-based foods due to issues like the lack of availability, taste, and convenience of vegan foods. However, others recognized that it is becoming easier to find tasty options.

Some people talked about dietary change feeling insignificant in the face of the scope of animal farming, but also the fact that they could make a change that would make a difference for at least some animals. On that front, the information provided on the tour about the number of animals one person can save a year seemed to be helpful.

People generally appreciated the gentle way that Farm Sanctuary helped to move them along the path to living a more animal-friendly life. As mentioned above, a number of people pointed out that the tour was the right balance-presenting information about factory farming, but without being too pushy.

"I think a large criticism that people think about the vegan community is that they can be judgmental and they try and put it in your face if you don't follow that same lifestyle as them. They think that maybe they're going to change you right then and there. It was nice to have that more positive aspect to it."

"I remember a lot of people back in my younger days who'd become animal rights activists can be kind of hostile or bitter if you're not complete vegan or completely cruelty-free. I didn't get that vibe here. I'm glad that they didn't do that, just to encourage people to make any change. [laughter]"

Despite the recognition that dietary changes can be difficult, a very common theme among participants was the idea that the tour helped to reorient and refocus their efforts. This was true across the spectrum of diets-people generally felt that they were being gently guided towards a more animal-friendly option. 
"It's inspiration to do better with our choices [....] It just sort of grounds me so it just brings me back to why we do what we do and why we've made the decisions we've made."

"I often wrestle with my own food choices: eating meat, not eating meat, trying to eat meat that's from a place that I trust, all that stuff. Coming back here is a way to reorient."

\section{Rejuvenation For Vegans And Vegetarians}

A theme among long-time vegans and vegetarians was a reinvigoration of their goals after visiting the sanctuary. They recognized that animal advocacy can be difficult, as can sticking to a diet that is challenging at times and that may not be supported by family and friends. They felt that being on the tour, at peace and with the animals, helped them refocus and recharge.

"I think it keeps me invigorated. I was heavily into animal rights in my 20 s. I'm in my 40 s now. Some of that kind of died [...] It just kind of wears people down. I think when I come to things like this, I get a little bit reinvigorated again."

\section{Conclusions}

Results from the on-site surveys, the follow-up surveys, and the qualitative interviews tell a consistent story: Sanctuary tours can be highly satisfying experiences for most people, and can lead to important changes in attitudes, intentions, and behaviors. Participant feedback suggested that the key elements were one-on-one contact with the animals, educational videos and information on animal cruelty, and balanced messaging on plant-based lifestyles. All of these factors appeared to shape their beliefs and diets in order to help animals.

\section{One-On-One Contact With Animals}

Learning about the animals and interacting with them is central to the tour experience. Participants generally wanted more time with the animals, but this desire has to be balanced with the number of tours on a given day as well as animal-centric concerns. Sanctuaries would likely be wise to foster the sense of connection between their attendees and the animals they care for by providing direct contact (when possible), general information, backstories on specific animals, and anecdotes about their personalities. 


\section{Education About Animal Cruelty}

Although there were a few participant comments reporting that the animal cruelty messages were too strong, these were outweighed by praise for these aspects of the tour, and also the resulting positive changes in people's beliefs and behaviors. That said, we believe that it is important for sanctuaries to work to find the balance and the right message for their audience--the goal appears to be to open people's eyes while not pushing them away. Farm Sanctuary appears to have found a balance between these outcomes though years of experience, and other sanctuaries can do the same by understanding people's response to the different aspects of their own tour. This can be best determined through a formal evaluation, but a lot of valuable information can be gained from well-designed feedback forms or even purposeful, objective conversations with tour attendees.

\section{Balanced Information About Plant-Based Diets}

There was also positive feedback about the inclusion of vegan food in the gift shop at the end of the tour. We feel this element of a tour can help people make the connection between the "why" of plant-based diets and the "how" of diet change. People are likely most open to dietary alternatives while the experiences at a sanctuary are still fresh, and taking that first step of trying something new in that context may lead to a positive habit in the future. Selling food products--either prepared and/or as groceries--can also add an additional revenue stream for a sanctuary.

Overall, the sanctuary tour experience helps people form meaningful connections with animals in a way that is not possible through other outreach activities. The results of this study provide evidence that diets, attitudes, and intentions do indeed change in meaningful ways after people leave the sanctuary. Therefore, experiential learning and balanced messaging around plant-based lifestyles at farm sanctuaries can help form meaningful connections with animals and lead to positive changes over time.

\section{Limitations}

There are a few limitations to bear in mind with this analysis.

\section{Self-Report}

First, because it is entirely survey research, all the findings are self-reported, which means they are subject to human error and misreporting, whether intentional or not. For instance, participants may be more likely to report an intention to change their diet than to actually do it, or to exaggerate actual changes they have made. Some of these issues could be avoided with a control group, but this was not feasible with this research design. Instead, we used a two-group 
pretest-posttest design for the on-site surveys so that the immediate impact of the tour could be compared to a similar group who had not taken the tour. This reduces some of the concern about interpretation.

\section{Non-Response}

The second limitation is non-response bias when interpreting the results of the three-month follow-up survey: If the people who completed the follow-up differed from those who didn't, it could affect the interpretation of results. The response rate for the follow-up survey was $39 \%$, which is not bad for this type of research, but leaves a lot of room for non-response bias. We conducted an analysis to look for significant differences between the people who did and did not participate in the follow-up survey.

Compared to people who did not complete the follow-up survey, the people who did were:

- Less likely to be under 18;

- More likely to be female;

- More likely to be vegan, vegetarian, or reducetarian/flexitarian/semi-vegetarian;

- More likely to want to reduce their consumption of animal products and more confident in their ability to do so; and

- More satisfied with the tour.

Therefore, the results from the follow-up must be interpreted with caution, because they come from a group of people who were already consuming fewer animal products and were more amenable to change than those who didn't respond. That said, the results are still interpretable for that particular group: those who were on their way toward change reported that they continued to follow through over time.

Importantly, however, the risk of non-response bias in the on-site sample is very low because of how the surveys were administered. Although participation was optional, the surveys were short and handed out on clipboards at the end of the tour to all participants, so few people refused to complete them.

\section{Generalizability To Other Sanctuaries}

Overall, while the above limitations are important to bear in mind, the results of the quantitative and qualitative analyses are highly consistent in their message that Farm Sanctuary's tours have a positive impact on visitors' understanding of farmed animal suffering and intentions to change their behavior. The final limitation deals with generalizability.

Interviews revealed the aspects of the Farm Sanctuary visitor experience that were particularly influential on visitors: putting farmed animal abuse up front, interacting with individual, happy 


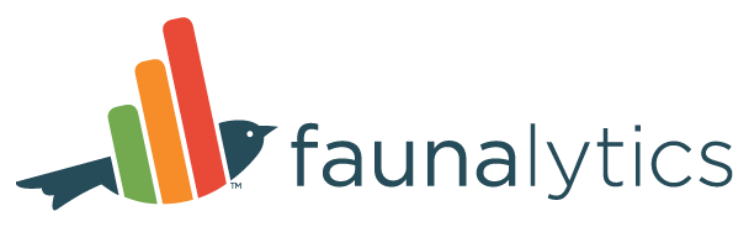

animals, and a message of diet change framed in a positive, incremental way. These elements are clearly important in achieving the observed results, so it must be stressed that if other farm sanctuaries do not provide a similarly interactive, advocacy-focused visitor experience, these positive outcomes may not apply. 